\title{
L'Afrique du siècle des Lumières: savoirs et représentations. Sous la direction de Catherine Gallouët, David Diop, Michèle Bocquillon et Gérard Lahouati
}

\section{Maria Immacolata Spagna}

\section{OpenEdition}

\section{Journals}

Edizione digitale

URL: http://journals.openedition.org/studifrancesi/6297

DOI: 10.4000/studifrancesi.6297

ISSN: 2421-5856

\section{Editore}

Rosenberg \& Sellier

\section{Edizione cartacea}

Data di pubblicazione: 1 novembre 2010

Paginazione: 555

ISSN: 0039-2944

\section{Notizia bibliografica digitale}

Maria Immacolata Spagna, «L'Afrique du siècle des Lumières: savoirs et représentations. Sous la direction de Catherine Gallouët, David Diop, Michèle Bocquillon et Gérard Lahouati», Studi Francesi [Online], 162 (LIV | III) | 2010, online dal 30 novembre 2015, consultato il 13 janvier 2021. URL: http:// journals.openedition.org/studifrancesi/6297 ; DOI: https://doi.org/10.4000/studifrancesi.6297

Questo documento è stato generato automaticamente il 13 janvier 2021.

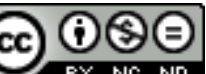

Studi Francesi è distribuita con Licenza Creative Commons Attribuzione - Non commerciale - Non opere derivate 4.0 Internazionale. 


\title{
L'Afrique du siècle des Lumières: savoirs et représentations. Sous la direction de Catherine Gallouët, David Diop, Michèle Bocquillon et Gérard Lahouati
}

\author{
Maria Immacolata Spagna
}

\section{NOTIZIA}

L'Afrique du siècle des Lumières: savoirs et représentations. Sous la direction de Catherine GALLOUËT, David DIOP, Michèle BOCQUILLON et Gérard LAHOUATI, Oxford, Voltaire Foundation, 2009 («SVEC» 2009: 05), pp. 307.

1 Il presente volume raccoglie le riflessioni di un gruppo di studiosi sulle origini, le funzioni ideologiche e la diffusione delle rappresentazioni che gli uomini del Settecento avevano dell'Africa, nonché sulla genealogia e le condizioni della conoscenza dei suoi abitanti.

2 Nella prima parte (pp. 1-47), intitolata «Questions de méthodologie», Jean-Claude HALPERN mostra, nel suo articolo sugli approcci usati nel '700 per lo studio dell'Africa, che le rappresentazioni del continente africano sono il risultato di una sintesi tra saperi antichi e moderni. David DIOP, nel suo studio del Voyage au Sénégal di Michel Adanson, sottolinea come il botanico, preoccupato di soddisfare le aspettative dell'Académie royale des sciences fornendo un'ampia gamma del lessico della flora e della fauna dell'Africa, abbia trascurato i problemi legati al rapporto tra gli africani e la natura e il loro livello di conoscenza dei metodi e delle tecniche di lavoro. Da parte sua, Catherine GALLOUËT, passando in rassegna i diversi modi di rappresentazione della regina di 
Angola, Zingha, ne identifica una serie di tratti comuni nei vari racconti europei del XVIII secolo, che si ripropongono ancora oggi.

3 In questa prospettiva, gli interventi di Thomas HALliER, Gérard LAHOUATI, Siegfried HUIGEN e Jean-Michel RACAULT, riuniti nella seconda parte (pp. 49-100), intitolata «Histoire et Anthropologie», cercano di mostrare come i discorsi storici e antropologici fatti via via sull'Africa, apparentemente innovativi, siano stati in realtà la ripetizione degli stessi schemi interpretativi.

4 La terza parte (pp. 101-153), «Territoires de la fiction», mette in evidenza come le relazioni di viaggiatori fittizi si rifacciano ai saperi e alle rappresentazioni delle vere relazioni di viaggio. Stéphan PASCAU lo dimostra per il filosofo Henri-Joseph Dulaurens, Emmanuelle SAUVAGE per Rétif de la Bretonne, Pierre cambou lo rintraccia nella rappresentazione degli africani presente nei racconti di Voltaire.

5 Nella quarta parte (pp. 155-253) intitolata «Savoirs et discours esthétiques», il saggio di Francesco Paolo ALEXANDRe MADONIA sui dibattiti attorno alla concezione del 'Bello' sottolinea come il relativismo del gusto, piuttosto che rafforzare l'uguaglianza degli uomini, abbia ribadito l'idea della bellezza della razza bianca a discapito di quella nera. Gli altri articoli, incentrati soprattutto sulle rappresentazioni nei racconti di viaggio, sottolineano come l'iconografia dell'epoca sia stereotipata perché prodotta generalmente, come ribadisce Malais, all'interno degli appartamenti da artisti che non hanno mai messo piede in Africa. Queste rappresentazioni si assomigliano a tal punto da continuare a diffondere una vecchia immagine dell'Africa e dei suoi abitanti.

6 Dai vari contributi di questo interessante volume si evince che le rappresentazioni dell'Africa e degli africani proposte dagli uomini del Settecento sono denotate negativamente e costituiscono la fonte dei pregiudizi che si ripercuotono nelle visioni razziste del popolo africano che continuano a persistere nel mondo di oggi. 